\title{
PENGARUH MEDIA SOSIAL, PERHATIAN ORANG TUA, DAN MINAT BELAJAR TERHADAP HASIL BELAJAR MATA PELAJARAN IPS TERPADU
}

\author{
Oktaviana \\ e-mail: oviana009@gmail.com \\ Rusno \\ e-mail: rusno@unikama.ac.id \\ Riril Mardiana Firdaus \\ e-mail: ririlmardiana@unikama.ac.id
}

(Program Studi Pendidikan Ekonomi, Fakultas Ekonomika dan Bisnis, Universitas Kanjuruhan, Malang)

\begin{abstract}
The purpose of the study was to reveal social media, parents' attention, and interest in learning about student learning outcomes. With the existence of good social media accompanied by the attention of good parents and good learning outcomes, it will improve student learning outcomes. This study aims to determine the effect of social media, parents' attention, and interest in learning towards the learning outcomes of social studies subjects for VII grade students of Ma'arif 02 Middle School Malang. This type of research uses ex-post facto research. The population in this study were students of class VII at Ma'arif 02 Islamic Junior High School in Malang, amounting to 320 students with a research sample of 79 students. Based on the calculation results, it is known that: There is the influence of social media, parents' attention, and interest in learning towards learning outcomes. The results of multiple regression analysis revealed that the F-count value was 9.572 with a significant level of $0.000<0.05$, so it can be said that social media (X1), parents' attention (X2), and interest in learning (X3) had a simultaneous or partial influence on learning outcomes $(Y)$.
\end{abstract}

Keywords : Social media, Parents' attention, Interest in learning, Learning outcomes

\begin{abstract}
Abstrak: Tujuan penelitian untuk mengungkapkan media sosial, perhatian orang tua, dan minat belajar terhadap hasil belajar siswa. Dengan adanya media sosial yang baik disertai dengan perhatian orang tua yang baik dan hasil belajar yang baik maka akan meningkatkan hasil belajar siswa. Penelitian ini bertujuan untuk mengetahui pengaruh media sosial, perhatian orang tua, dan minat belajar terhadap hasil belajar mata pelajaran IPS siswa kelas VII SMP Ma'arif 02 Kota Malang. Jenis penelitian menggunakan penelitian ex-post-facto. Populasi dalam penelitian ini adalah siswa kelas VII di SMP Islam Ma'arif 02 Kota Malang yang berjumlah 320 siswa dengan sampel penelitian yang berjumlah 79 siswa. Berdasarkan hasil perhitungan, diketahui bahwa: Terdapat pengaruh media sosial, perhatian orang tua, dan minat belajar terhadap hasil belajar. Hasil analisis regresi berganda diketahui nilai F-hitung sebesar 9,572 dengan tingkat signifikan 0,000<0,05, maka dapat dikatakan bahwa media sosial (X1), perhatian orang tua (X2), dan minat belajar (X3) memiliki pengaruh secara simultan maupun parsial terhadap hasil belajar $(Y)$.
\end{abstract}

Kata kunci : Media sosial, Perhatian orang tua, Minat belajar, Hasil belajar 


\section{PENDAHULUAN}

Pendidikan di Indonesia sangat mempengaruhi kehidupan yang ada di masyarakat. Melalui pendidikan seseorang akan mendapatkan bekal dalam menghadapi kehidupan di masa mendatang karena dengan pendidikan kehidupan seseorang diharapkan akan lebih baik. Usaha yang dilakukan adalah dengan mendirikan lembaga pendidikan. Sekolah merupakan lembaga pendidikan formal yang memegang peranan sangat penting dalam meningkatkan kualitas sumber daya manusia. Dari hasil belajar sangatlah penting, karena akan disajikan indikator keberhasilan baik bagi guru maupun siswa. Namun untuk memperoleh semua itu tidaklah mudah, karena mengingat adanya perbedaan yang dimiliki setiap individu, dengan perbedaan itu maka akan menyebabkan hasil belajar yang berbeda-beda, yaitu ada yang tinggi, sedang bahkan rendah.

Media sosial dianggap menarik dan menyenangkan bagi mereka yang sering kali menggunakannya, mereka menggukan media sosial sebagai alat penambah bahan ajar mereka dengan tujuan untuk menambah ilmu pengetahuannya agar dapat meningkatkan hasil belajarnya di sekolah. SMP Ma'arif 02 Kota Malang memiliki banyak misi yang harus di capai. Salah satu misinya adalah Mewujudkan lulusan memiliki prestasi akademik dan non akademik tingkat nasional.

Kesibukan orang tua siswa kelas VII SMP Islam Ma'arif 02 Kota Malang dalam kegiatan di rumah maupun di luar rumah, baik itu kegiatan sosial maupun kegiatan mencari nafkah untuk mencukupi kebutuhan karena tuntutan jaman. Kondisi yang seperti ini sangatlah mempengaruhi dalam perkembangan kemampuan anak, karena dengan banyaknya kesibukan orang tua maka akan mengurangi pemberian perhatian orang terhadap anak. Perhatian yang seharusnya dilakukan oleh orang tua adalah perhatian yang bersifat acceptance, yaitu perhatian yang penuh dengan rasa kasih saying yang tulus, menempatkan anak yang terpenting dalam keluarga, memberikan arahan kepada anak, serta selalu membangun hubungan harmonis dalam hubungan keluarga. Dengan demikian, akan tercipta suasana yang nyaman untuk anak, yang akan mendorong anak untuk lebih semangat belajar. Arahan dari orang tua tentang pentingnya belajar dan di sertai bimbingan dari orang tua terhadap anak akan menimbulkan semangat belajar yang tinggi pada anak, sehingga anak akan mudah dalam mencapai hasil belajar yang optimal.

Minat belajar yang rendah akan mengakibatkan hasil belajar siswa juga rendah sebaliknya minat belajar yang tinggi akan mengakibatkan hasil belajar yang baik. Timbulnya minat belajar disebabkan berbagai hal, antara lain karena keinginan yang kuat untuk memperoleh sesuatu yang hendak di capai termasuk hasil belajar yang tinggi. Berdasarkan penjelassan diatas, maka bisa ditarik kesimpulan bahwa antara media sosial, perhatian orang tua, dan minat belajar terhadap hasil belajar saling berkaitan dalam mata pelajaran ips terpadu. Dalam penelitian kali ini, peneliti memlih lokasi di SMP Islam Ma'arif 02 Kota Malang alternative pertama karena jarak antara tempat tinggal dan lokasi sekolah dekat, kedua sekolah tersebut memiliki populasi yang cukup banyak untuk diteliti oleh peneliti, ketiga peneliti ingin mengetahui hasil belajar mata pelajaran Ips SMP Islam Ma'arif 02 yang notebennya adalah sekolah menengah pertama yang berada di Kota Malang.

Tujuan penelitian yang ingin dicapai dalam penelitian ini adalah (1) untuk menganalisis pengaruh media sosial, perhatian orang tua, dan minat belajar terhadap hasil belajar mata pelajaran Ips siswa kelas VII di SMP Islam Ma'arif 02 Kota Malang. (2) untuk menganalisis pengaruh media sosial terhadap hasil belajar mata pelajaran Ips siswa kelas VII di SMP Islam Ma'arif 02 Kota Malang. (3) untuk menganalisis pengaruh perhatian orang tua terhadap hasil belajar mata pelajaran Ips siswa kelas VII di SMP Islam Ma'arif 02 Kota Malang. (4) untuk menganalisis pengaruh perhatian minat belajar terhadap hasil belajar mata pelajaran Ips siswa kelas VII di SMP Islam Ma'arif 02 Kota Malang. 


\section{TINJAUAN PUSTAKA}

\section{Hasil Belajar}

Salah satu alat yang dapat digunakan untuk mengukur tingkat keberhasilan pendidikan adalah hasil belajar. Keberhasilan pencapaian belajar ditandai dengan hasil belajar yang baik. Apabila dalam proses belajar siswa mendapatkan hasil yang kurang baik maka pembelajaran belum berlajaran berhasil. Hasil belajar dijadikan tolak ukur bagi guru untuk mengetahui mutu pendidikan dan cara meningkatkannya hasil belajar siswa. Dari hasil pengajaran guru kepada siswa dapat di ukur, seperti yang tertuang dalam nilai rapor dan nilai angka ijazah.

Pembelajaran dapat dikatakan berhasil apabila ditunjukkan oleh siswa merasa berasil dan memperoleh kepuasan dalam belajar, dan hal ini yang akan mendorong siswa untuk belajar baik lagi. Dan tentunya keberhasilan ini dibuktikan dengan tercapainya tujuan intruksional dari suatu bahan pembelajaran. (Anitah, 2009) berpendapat bahwa hasil belajar harus menunjukkan suatu perubahan tingkah laku atau perolehan perilaku yang baru dari siswa yang bersifat menetap, fungsional, positif, dan disadari. Ilmu sosial atau ilmu pengetahuan sosial (IPS) adalah sekelompok disiplin akademis yang mempelajari aspek-aspek yang berhubungan dengan manusia dan lingkungan sosialnya. Jadi, berdasarkan pengertian diatas ruang lingkup yang dikaji adalah manusia dan lingkungan sosialnya yang mencangkup manusia itu sendiri dan hal-hal yang ada di sekitarnya.

Belajar merupakan proses kemampuan yang dialami oleh siswa menuju ke arah yang lebih baik. Menurut (Hamalik, 2011). Diketahui bahwa belajar merupakan suatu proses yang dilakukan secara sadar baik perubahan berupa tingkah laku maupun pengetahuan karena adanya interaksi antara individu dengan lingkungannya.

\section{Media Sosial}

Media Sosial adalah suatu wadah untuk menghubungkan banyak orang dalam lingkungan sosial secara online melalui penggunaan website (douglas, 2010) Social Networking Site (SNS), atau media sosial didefinisikan sebagai suatu layanan berbasis web yang memungkinkan setiap individu untuk membangun hubungan sosial melalui dunia maya seperti membuat suatu profil tentang dirinya sendiri, menunjukkan koneksi seseorang dan memperlihatkan hubungan apa saja yang ada antara satu member dengan member lainya dalam sistem yang disediakan (Boyd \& Ellison, 2008). (Nasrullah, 2015) menyatakan bahwa media sosial merupakan medium di internet yang mengunjungi pengguna mempresentasikan dirinya maupun berinteraksi, bekerja sama, berbagi, berkomunikasi dengan pengguna lain, dan membentuk ikatan sosial secara virtual.

Media sosial yang populer saat ini antara lain dunia virtual seperti: virtual shop dan virtual learning; Wiki seperti; Wikipedi; jejaring sosial seperti: facebook, google plus, twitter, instagram, whatsapp, blackberry messanger (BBM), youtube dan line. Media sosial akan mengajak siapa saja yang tertarik untuk berpertisipasi dengan memberi kontribusi dan feedback secara terbuka, memberi komentar, serta membagi informasi dalam waktu yang cepat dan tak terbatas. Kini untuk mengakses seperti: dunia virtual seperti: virtual shop dan virtual learning; Wiki seperti: Wikipedia; jejaring sosial seperti: facebook, google plus, twitter, instagram, whatsapp, blackberry messanger (BBM) youtube dan line. Media sosial juga mulai tampak menggantikan peranan media masa konvensional dalam menyebarkan berita-berita. 


\section{Perhatian Orang Tua}

Kesibukan orang tua sekarang dalam kegiatan di luar rumah, baik itu kegiatan sosial maupun kegiatan mencari nafkah untuk mencukupi kebutuhan karena tuntutan jaman. Purwanto (2011: 59) mengatakan bahwa "Kemampuan atau intelegensi akan dapat berkembang tergantung pada kemauan anak itu sendiri, dan kemauan anak itu dapat dipengaruhi atau diarahkan orang tuanya. Tanpa dukungan dari orang tuanya kemampuan anak tidak akan dapat berkembang seoptimal mungkin." Tanpa dukungan orang tua kemampuan siswa tidak akan berkembang seoptimal mungkin. Masalah kedua adalah kurangnya pengarahan, dorongan, dan motivasi orang tua untuk menumbuhkan semangat belajar anak. "Motivasi akan menentukan tercapainya minat dan bakat anak dan didukung dengan adanya pengarahan, dorongan atau motivasi dari orang tua, anak akan menjadikan belajar sebagai aktifitas menyenangkan".

Purwanto (2011: 60) Motivasi belajar yang kurang, maka akan mempengaruhi prestasi belajar yang diperoleh. Masalah lainnya adalah kurangnya sarana dan prasaran yang disediakan oang tua untuk mendukung kegiatan belajar di rumah.

\section{Minat Belajar}

Minat merupakan suatu kegiatan yang dilakukan oleh siswa secara tetap dalam melakukan proses belajar. Seseorang yang memiliki minat terhadap kegiatan tertentu cenderung memberikan perhatian yang besar terhadap kegiatan tersebut. Siswa yang memiliki minat terhadap subjek tertentu cenderung untuk memberikan perhatian yang lebih besar terhadap subjek tertentu.

\section{METODE}

Jenis penelitian yang digunakan adalah explanatory research. Penelitian telah dilaksanakan di SMP Islam Ma'arif 02 Kota Malang. Populasi berjumlah 320 siswa dan sampel penelitian 79 siswa yang ditentukan dengan teknik proportional random sampling. Variabel dalam penelitian ini terdiri dari tiga variabel bebas (independent variable). Variabel tersebut diberi simbol X1, X2 dan X3, yaitu media social, perhatian orang tua, dan minat belajar. Variabel terikat (dependent variable) diberi simbol Y yaitu hasil belajar siswa. Data variabel $Y, X 1$ dan $X 2$ dikumpulkan menggunakan instrumen kuesioner (angket) sedangkan X3 menggunakan dokumentasi.

\section{HASIL DAN PEMBAHASAN}

Berdasarkan permasalahan tersebut, analisis kontribusi media sosial, perhatian orang tua, dan minat belajar terhadap hasil belajar siswa. Berikut ini adalah hasil analisis data dan pengujian hipotesis yang telah dilakukan.

Berdasarkan hasil perhitungan dapat diketahui nilai: a $=35,163, \mathrm{~b} 1=, 158$ b2 $=081$, b3 =,180 maka dapat disusun persamaan regresi linear berganda sebagai berikut:

$$
\begin{gathered}
\mathrm{Y}=\mathrm{a}+\mathrm{b} 1 \mathrm{X} 1+\mathrm{b} 2 \mathrm{X} 2+\mathrm{b} 3 \mathrm{X} 3+\mathrm{e} \\
\mathrm{Y}=35,163+0,158(\mathrm{X} 1)+0,081(\mathrm{X} 2)+0,180(\mathrm{X} 3)
\end{gathered}
$$

Konstanta sebesar 35,163 memiliki arti jika variabel X1, X2 dan X3 atau jika variabel X1, X2 dan X3 bernilai nol, maka nilai variabel dependen (Y) akan sebesar 35,163. Nilai koefisien regresi variabel X1 (media sosial) sebesar 0,158, artinya jika variabel X1 ditingkatkan 1 akan menyebabkan peningkatan hasil belajar sebesar 0,158. Nilai koefisien regresi variabel X2 (perhatian orang tua) sebesar 0,081, artinya jika variabel X2 ditingkatkan 1 akan menyebabkan peningkatan hasil belajar 
sebesar 0,081. Nilai koefisien regresi variabel X3 (minat belajar) sebesar 0,180, artinya jika variabel X3 ditingkatkan 1 akan menyebabkan penurunan hasil belajar sebesar -0,180.

Jika dilihat dari nilai hasil analisis uji $\mathrm{F}$ didapat statistik nilai $\mathrm{F}$ sebesar 9,572 dengan tingkat signifikan 0,000 karena tingkat signifikan lebih kecil dari 0.05, maka hasil penelitian ini menolak hipotesis penelitian Ho1 dan tidak menolak hipotesis penelitian Ha1 yaitu: ada pengaruh yang signifikan secara simultan antara media sosial, perhatian orang tua, dan minat belajar terhadap hasil belajar siswa kelas VII di SMP Islam Ma'arif 02 Kota Malang.

Nilai Koefisien Determinasi (R Square) menunjukkan besarnya pengaruh seluruh variabel bebas yaitu variabel media sosial (X1), perhatian orang tua (X2), minat belajar (X3) memiliki nilai koefisien korelasi 0,526 mendekati 1 memiliki makna bahwa variabel bebas media sosial (X1), perhatian orang orang tua $(\mathrm{X} 2)$, minat belajar $(\mathrm{X} 3)$ secara bersama-sama memiliki hubungan yang kuat dengan variabel terikat hasil belajar (Y), Nilai koefisien determinasi (R Square) menunjukkan besar kontribusi seluruh variabel bebas yaitu media sosial (X1), perhatian orang tua (X2), minat belajar (X3) terhadap hasil belajar (Y), jadi R Square 0,277 memiliki makna media sosial (X1), perhatian orang tua (X2), minat belajar (X3) mampu memberikan kontribusi sebesar 27,7\% terhadap hasil belajar (Y) dengan demikian sisanya sebesar $72,3 \%$ ditentukan oleh variabel lain yang tidak diteliti.

Untuk mengetahui pengujian hipotesis pertama, maka menggunakan uji $\mathrm{F}$ dan untuk menguji hipotesis ke dua, tiga, dan empat menggunakan uji t.

\section{Pengaruh media sosial, perhatian orang tua, dan minat belajar terhadap hasil belajar}

Hasil statistik menunjukkan bahwa ada pengaruh yang signifikan pengaruh media sosial, perhatian orang tua, dan minat belajar terhadap hasil belajar mata pelajaran Ips Terpadu siswa kelas VII SMP Islam Ma'arif 02 Kota Malang digunakan uji F. Nilai F-hitung sebesar 9,572 dengan tingkat signifikan 0,000 karena tingkat signifikan lebih kecil dari 0.05, maka hasil penelitian ini menolak hipotesis penelitian Ho1 dan tidak menolak hipotesis penelitian Ha1, hasilnya dapat disimpulkan bahwa media sosial, perhatian orang tua, dan minat belajar terhadap hasil belajar siswa kelas VII SMP Islam Ma'arif 02 Kota Malang.

\section{Pengaruh media sosial terhadap hasil belajar}

Hasil statistik menunjukkan bahwa ada pengaruh yang signifikan secara parsial antara media sosial terhadap hasil belajar mata pelajaran IPS. Hal tersebut ditunjukkan dengan nilai t-hitung sebesar 2,260 dengan nilai signifikan sebesar 0,027 karena tingkat signifikan < 0,05 maka Ho2 ditolak dan Ha2 diterima.

\section{Pengaruh perhatian orang tua terhadap hasil belajar}

Hasil statistik menunjukkan bahwa ada pengaruh yang signifikan secara parsial perthatian orang tua terhadap hasil belajar siswa mata pelajaran IPS kelas VII SMP Islam Ma'arif 02 Kota Malang. Hal tersebut ditunjukkan dengan nilai sebesar 2,339 dengan tingkat signifikan sebesar 0,022 atau signifikan $<0,05$ dan $\mathrm{Ho3}$ ditolak dan Ha2 diterima.

\section{Pengaruh minat belajar terhadap hasil belajar}

Berdasarkan uji t diperoleh hasil bahwa terdapat pengaruh yang signifikan secara parsial minat belajar terhadap hasil belajar siswa kelas VII SMP Islam Ma'arif 02 Kota Malang. Hal tersebut ditunjukkan dengan nilai t-hitung sebesar 2,180 dengan tingkat signifikan sebesar 0,032 atau signifikan $<0,05$ maka Ho4 ditolak dan Ha4 diterima. 


\section{KESIMPULAN}

Berdasarkan hasil analisis yang telah dikemukakan pada bab sebelumnya, maka dapat ditarik beberapa kesimpulkan bahwa ada pengaruh yang signifikan secara simultan antara media sosial, perhatian orang tua, dan minat belajar terhadap hasil belajar mata pelajaran IPS di SMP Islam Ma'arif 02 Kota Malang. Berdasarkan hasil penelitian ini, maka saran yang diajukan adalah (1) Hasil penelitian ini menunjukan bahwa media sosial merupakan sebagai alat penambah bahan ajar mereka dengan tujuan untuk menambah ilmu pengetahuannya agar dapat meningkatkan hasil belajarnya di sekolah. Dengan demikian media sosial juga memiliki peran penting bagi sekolah agar dapat menambah pengetahuan siswa di sekolah dan dapat belajar lebih efektif sesuai dengan tuntutan jaman. (2) Agar siswa mengetahui seberapa besar pengaruh perhatian orang tua terhadap hasil belajar yang diperoleh di sekolah untuk dapat bersaing sehat dengan teman-teman di sekolah. (3) Siswa diharapkan untuk dapat meningkatkan kemampuannya secara akademik agar dapat besaing secara sehat baik di lingkungan sekolah maupun di luar sekolah. (4) Bagi peneliti selanjutnya, penelitian ini masih dapat dikembangkan lagi melalui variabel yang belum diteliti oleh penelitian ini. Variabel yang dapat digunakan untuk hasil belajar adalah pemanfaatan internet, prestasi belajar, motivasi belajar, lingkungan sosial dan teman sebaya.

\section{DAFTAR PUSTAKA}

Afriani, Rio. (2014). Pengaruh Pembelajaran Multimedia Interaktif Terhadap Hasil Belajar Siswa (Jurnal). UNILA: Lampung.

Ahmadi. (2012). Pengaruh Fasilitas Belajar dan Intensitas Belajar terhadap Prestasi Belajar Mahasiswa Program Studi Pendidikan Akuntansi Angkatan 2008 Univesitas Muhammadiyah Surakarta. Surakarta: Universitas Muhammadiyah Surakarta.

Anitah, Sri. (2009). Media Pembelajaran. Surakarta: Panitia Sertifikat Guru Rayon13 FKIP UNS Surakarta.

Boyd Danah M, Ellison Nicole B. (2007). Sosial Network Sites. Definition, History, and Scholarship. dipetik September 20, 2008, dari Jurnal of Computer Mediated Communication: http://jcmc.indiana.edu/vo113/issues1/boyd.ellison.html.

El-Badawy, (2015). The Impact Of Social Media on the Academic Development of School Student. International Journal of Business Administration, 6, 1-8.

Fatimah, F, A. (2011). Hubungan Kebiasaan Sarapan Pagi dan Jajan dengan Status Gizi Anak Sekolah Dasar di SD Negeri Kledikan Depok Sleman Yogyakarta. Fakultas Respati: Yogyakarta.

Fitrayati, (2016). Pengaruh Minat Belajar dan Jam Belajar Terhadap Prestasi Belajar Siswa Pada Mata Pelajaran Ekonomi Siswa Kelas XI IPS 3 SMA Negeri Kesamben Kabupaten Jombang. Pendidikan Ekonomi, 4(3), 1-6.

Karjaluoto, Eric. (2008). A Prime in Social Media. Examining the Phenomenon, its Relevance,

Promise and Risks: Diakses pada 20 Maret 2012 dari http://www.smashlab.com/media/white-papers/a-primer-in-social-media.

Mulyasa, E. (2008). Menjadi Guru Profesional Menciptakan Pembelajaran Kreatif dan Menyenangkan. Bandung: PT. Remaja Rosdakarya. 
Nasrullah, Rulli. (2015). Menjadi Guru Profesional Menciptakan Pembelajaran Kreatif dan Menyenangkan. Bandung: Simbiosa Rekatama Media.

Qomariyah. (2015). Pengaruh Perhatian Orang Tua Terhadap Prestasi Belajar Menjahit pada siswa SMPN 2 Mojogedeng Kabupaten Karanganyar. Keluarga, 1(1), 1-7.

Ramdhani. (2016). Pengaruh Sosial Media (Facebook) Terhadap Prestasi Belajar Mahasiswa Ilmu Komunikasi Univesitas Singaperbangsa (UNSIKA) Karawang. Politikom Indonesiana, $1(1), 1-13$.

Sarwoko, (2008). Manajemen Keuangan (Dasar-dasar Pembelajaran Perusahaan). BPEE: Yogyakarta.

Suwardi. (2012). Faktor-Faktor yang Mempengaruhi Hasil Belajar Siswa Kompentensi Dasar Ayat Jurnal Penyesuaian Mata Pelajaran Akuntansi Kelas XI IPS di SMA Negeri 1 Bea Kudus. hppt://journal.unnes.ac.id/sju/index.php/eeaj, 2, 1-7.

Syah, Muhibbin. (2010). Psikologi Pendidikan dengan Pendekatan Baru. Bandung: PT. Remaja Rosdakarya.

Wulandari, (2016). He Effect Of Parents Attention And Learning Discipline On Economics Learning Outcomes" In modern times many teachers are having trouble with student learning outcomes. IOSR Journal of Research \& Method in Education (IOSR-JRME), 6(2), $1-5$.

Zarella, Dan. (2010). The Social Media Markeing Book. Oreilly Media: USA. 